\title{
KATEKIS DAN PASTORAL LINGKUNGAN HIDUP
}

Oleh: Frederikus Dhedhu, Lic.

\section{Abstraksi:}

entingnya menjaga keutuhan lingkungan merupakan isu dan perjuangan global. Ada sekian banyak lembaga sosial bertaraf nasional yang dengan sangat gigih memberikan animasi kepada masyarakat umum tentang pentingnya menjaga lingkungan hidup. Gereja sebagai salah satu bagian dari komunitas global mengambil bagian dalam usaha menjaga dan melestarikan lingkungan hidup. Para fungsionaris pastoral adalah bagian utuh dari Gereja dan menjadi subyek utama dalam konkretisasi cita-cita Gereja untuk menjaga dan melestarikan keutuhan lingkungan hidup. Tugas untuk menjaga dan merawat lingkungan salah satunya dibebankan kepada para katekis. Katekis menjadi ujung tombak Gereja dalam usaha mengambil bagian dalam isu global tentang pentingnya menjaga keutuhan lingkungan. Melalui artikel ini, penulis hendak mengedepankan tanggung jawab ekologis seorang katekis.

Kata kunci: Lingkungan hidup, katekis, pastoral ekologis, pengrusakan lingkungan, perbaikan ekologi, tanggung jawab ekologis.

\section{Pendahuluan}

Eklesiologi Vatikan II secara sangat mendasar telah meruntuhkan struktur lama yang berciri piramidal sekaligus melahirkan struktur baru yakni eklesiologi dengan ciri persekutuan, pelayanan, dan misi. Gereja adalah satu persekutuan, yang terlibat dalam pelayanan kepada dunia dan manusia, dan yang senantiasa bermisi mendirikan Kerajaan Allah di dunia. Karena itu semua umat terbaptis dipanggil untuk itu, walaupun dengan tugas, tanggung jawab, fungsi, dan peran berbeda (AA, 1988: 12). Sebagai umat yang telah dibaptis, para katekis terlibat dalam melaksanakan mandat ilahi: "Pergilah jadikanlah semua bangsa murid-Ku dan ajarlah mereka melakukan segala sesuatu yang Kuperintahkan kepadamu. Dan ketahuilah, Aku akan menyertai kamu senantiasa sampai pada akhir zaman” (Mat 28:19-22).

Dalam terang kata-kata Yesus di atas, katekis sebagai awam terdidik, dipanggil secara khusus untuk tugas pastoral Gereja. Katekis memiliki posisi penting dan strategis dalam karya pastoral Gereja.Keberadaan para katekis di tengah-tengah umat merupakan kehadiran dengan tugas khusus, yakni pengudusan dunia dari dalam laksana ragi (GS 2). Dalam konteks pengudusan dunia, Gereja telah meninggalkan konsep lama yang cenderung tertutup dalam kemapanannya, dan selanjutnya mengenakan konsep baru tentang pastoral yang dibingkai oleh misteri inkarnasi. Konsep baru tersebut mengamanatkan Gereja untuk tidak "lari dari dunia" tetapi diundang untuk "masuk ke dalam dunia" (berinkarnasi) untuk mewujudkan 
proses "inkulturasi". Sebab pewartaan Injil tanpa proses inkulturasi sesungguhnya merupakan suatu pengkhianatan pastoral.

Konsep inilah yang memengaruhi seluruh diskusi selama Konsili Vatikan II. Karena itu Konsili Vatikan II bukan hanya fakta sejarah tetapi lebih merupakan fakta iman, karena diyakini sebagai peristiwa rahmat; didalamnya Roh Kudus berkarya, menggerakan Gereja, mengubahnya secara pasti sesuai dengan mentalitas dan pilihan pastoralnya. Warisan paling berharga dari Konsili Vatikan II terwakili dalam visinya yang baru tentang Gereja sebagaimana dilukiskan dalam dokumen-dokumennya. Konsep baru tentang pastoral menjadi landasan utama bagi para katekis untuk terlibat dalam membangun dunia dan manusia yang lebih bermartabat melalui karya dan perutusan yang diterima dari Gereja. Konsep baru tersebut juga akan menggerakan para katekis untuk menjadikan semua bidang kehidupan manusia sebagai lahan garapan bagi tumbuh dan berkembangnya nilai-nilai kerajaan Allah, termasuk bidang lingkungan hidup (Lolonrian,2013: 121).

\section{Katekis}

\section{Siapakah katekis itu}

Katekis adalah seorang yang atas nama Gereja memberikan pelajaran agama dan melaksanakan karya pewartaan Gereja. Katekis berasal dari tengah dunia dengan segala tatanannya. Mereka dipilih khusus untuk mengambil bagian dalam tri-tugas Yesus Kristus yakni sebagai Imam, Nabi, dan Raja, serta menjadi garam dan terang bagi sesama. Mereka adalah pembina iman atau guru agama, yang menjalankan pembinaan atau pengajaran atas nama Gereja.Untuk tugas yang mulia itulah, kepada mereka masing-masing diberikan Missio Canonica, kuasa pewartaan oleh Uskup setempat (Sutam, 2015: 234). Paus Yohanes Paulus II dalam Ensiklik Redemptoris Missio menegaskan: "Katekis adalah saksi-saksi langsung dan pewarta-pewarta Injil yang tak tergantikan yang sebagaimana seringkali saya nyatakan dan alami dalam perjalanan-perjalanan misioner saya, merupakan kekuatan basis persekutuanpersekutuan Kristen, teristimewa di dalam Gereja-Gereja Muda". Paus berkeyakinan bahwa posisi para katekis sangat sentral dan strategis dalam kehidupan Gereja. Dalam dan melalui kehadiran para katekis Gereja hadir untuk menguduskan, mengajar dan memimpin umat (RM 73).

\section{Spiritualitas Katekis}

Pembicaraan tentang spiritualitas katekis merupakan hal yang sangat mendasar. Sebab tugas yang diemban oleh para katekis merupakan tugas yang dilaksanakan sepanjang hidup. Tugas katekis tidak sekadar satu pekerjaan, melainkan merupakan panggilan yang harus ditekuni setiap hari dalam kesetiaan yang total. Dalam konteks itu spiritualitas menjadi basis kekuatan bagi para katekis dalam menjalankan tugas pastoralnya. Dokumen Direktorium Kateketik Umum (DKU) mengatakan perihal mengenai spiritualitas katekis sebagai berikut: "Tugas yang dipercayakan kepada katekis menuntut daripadanya suatu kehidupan sakramental 
dan rohani yang semangat, suatu penghayatan doa dan perasaan yang mendalam akan keunggulan warta kristiani dan kekuatan yang dimilikinya". Spiritualitas katekis mengalir dari jenis pelayanannya, yang mengacu pada iman, pengharapan dan cinta kasih. Ekspresi dari spiritualitas tersebut menyata dalam sikap menentang yang jahat dalam diri sendiri, rendah hati, miskin dalam Roh, taat dan bijaksana. (Telaumbanua,1999: 170).

\section{Tugas Katekis}

Tugas Katekis adalah mengambil bagian dalam tri-tugas Yesus Kristus yakni sebagai imam, nabi dan raja (Chen, 2015: 42).

\section{Sebagai imam}

Tugas sebagai imam dari seorang katekis adalah mengambil bagian dalam tugas imamat Kristus. Peran utama imam ialah menguduskan. Tugas imamat seorang katekis (petugas pastoral) adalah menghadirkan karya pengudusan Allah dalam diri Putera-Nya Yesus Kristus, Sang Guru Ilahi dan Imam Agung, secara aktual dan kontekstual. Tugas pengudusan inilah yang selalu dijalankan oleh para katekis secara konkret melalui cara hidup yang saleh dan merasuki setiap relung hati umat beriman untuk hidup saleh dan berkenan di mata Tuhan lewat pelbagai kegiatan rohani seperti doa, ibadat dan karya amal. Jadi, tugas katekis sebagai imam adalah menguduskan dunia, menciptakan suasana yang ramah agar orang lain dapat menemukan pesan Allah didalam hatinya.

\section{Sebagai Nabi}

Tugas kenabian seorang katekis adalah untuk mewartakan sabda Allah dan memberikan kesaksian tentang Kristus melalui kata, sikap, dan perbuatan nyata sebagai konkretisasi kenabian Yesus Kristus di tengah tata dunia.Mereka juga mengajar dan mengembangkan kewibawaan Kristus. Melalui cahaya Roh Kudus mereka menjelaskan iman dan mengeluarkan harta yang baru dari perbendaharaan pewahyuan. Tugas dan panggilan sebagai pewarta sabda bagi seorang katekis adalah untuk memaklumkan kabar gembira sabda Allah, terutama kepada umat di mana Gereja mendelegasikan tugas itu kepadanya. Di sini katekis bertindak sebagai duta kasih Kristus dan Gereja untuk merealisasikan pesan pembebasan kepada umat dengan cara memperjuangkan nilai-nilai kebenaran di tengah tata dunia.

\section{Sebagai Raja}

Tugas katekis sebagai raja sangat berkaitan dengan kelimpahan wewenang dan otoritas untuk melanjutkan tugas sebagai wakil dan utusan Yesus Kristus untuk memimpin dan menggembalakan. Sebagai pemimpin dan gembala, katekis adalah pemersatu umat, pembela atau pelindung umat, mencari yang hilang, membalut yang luka, serta mengantar umat menuju kepenuhan hidup kristiani. Memberi kesaksian bahwa Allah sungguh-sungguh meraja dalam hidup dan pergumulan 
umat melalui sikap kepemimpinan yang menghimpun dan mempersatukan umat. Karena itu katekis hendaknya mampu menggerakkan umat untuk senantiasa hidup dalam suasana persatuan dan persaudaraan.

\section{Pastoral Lingkungan Hidup}

\subsection{Pastoral}

Terminologi pastoral menyiratkan upaya untuk mendampingi, mengasuh, melindungi, merawat, dan membimbing umat. Dalam sejarah Gereja aplikasi dari terminologi tersebut, sangat dipengaruhi oleh konteks di mana Gereja tumbuh dan berkembang. Karena itu patut digarisbawahi perkembangan konsep "pastoral" dalam kehidupan Gereja.

\subsubsection{Konsep Lama}

Konsep lama melihat pastoral hanya berkaitan dengan ketrampilan teknis penggembalaan umat tanpa melihat kaitannya dengan dunia di mana Gereja hidup dan berkembang. Konsep tersebut dipengaruhi oleh dua alasan (Fallico, 2006: 62):

\section{Alasan Historis}

Pada periode sebelum Konsili Vatikan II, Gereja lebih dilihat sebagai "satu institusi", berciri "piramidal dan monolitik". Di sana, pada bagian puncak berturutturut ada paus-uskup-imam-para religius dan di dasarnya umat awam, dengan martabat dan posisi lebih rendah. Semua kebijakan diputuskan pada tingkat atas, sedangkan pelaksanaannya pada tingkat bawah. Komponen pada tingkat bawah tidak memiliki peluang dan kemungkinan untuk menyalurkan pikiran dan aspirasi pastoralnya. Apa yang diputuskan dari atas dinyatakan final.

\section{Alasan Teologis}

Pada periode sebelum Konsili Vatikan II dunia dilihat secara negatif, sebagai tempat kegelapan dan dosa. Kemauan untuk merasul dalam dunia juga dilihat sebagai kesalahan dan dosa yang harus dijauhkan oleh setiap anggota Gereja. Karena itu pada masa itu kekudusan hanya diukur oleh kemampuan seseorang meninggalkan dunia dan mengasingkan diri serta mencari tempat yang sunyi dan nyaman agar tidak diganggu oleh berbagai macam persoalan hidup.

\subsubsection{Konsep Baru}

Konsep baru tentang pastoral bertolak dari peristiwa inkarnasi (Villata, 1998: 94). Berdasarkan konsep baru tersebut, pandangan tentang dunia, sejarah dan wilayah, berubah secara positif.

Dunia: Dunia adalah tempat manusia hidup. Dikehendaki oleh Allah karena cinta-Nya yang kekal. Dunia dilihat sebagai "locus teologicus" dan partner dari Gereja. Tanpa dunia tidak ada Gereja. Karena itu Gereja dan dunia menghasilkan sejarah bersama, berjalan bersama menuju kesempurnaan Kerajaan Allah.

Sejarah: Sejarah adalah ruang di mana Allah mengonkretkan cinta dan kesetiaan-Nya kepada manusia. Sejarah manusia dengan segala harapan dan kecemasannya 
adalah medan di mana kerajaan Allah dibangun. Kaum kristiani tidak bisa menarik diri dan menutup diri hanya dalam kemapanan Gereja demi privatisme tetapi dipangil untuk terlibat dalam sejarah umat manusia.

Wilayah: Wilayah dilihat sebagai tempat kemana Gereja diutus oleh Allah. Wilayah merupakan ruang vital di mana manusia merealisasikan eksistensinya; tempat di mana masyarakat mengarahkan dan membangun sejarahnya. Gereja dipanggil untuk "tinggal" dalam wilayah tertentu. "Tinggal" berarti mengambil bagian dalam hidup konkret masyarakat yang hidup di wilayah tersebut dengan segala suka dan dukanya.

\subsubsection{Ciri-ciri kegiatan pastoral}

Mengacu pada konsep pastoral yang baru, maka setiap karya pastoral selalu memiliki ciri-ciri sebagai berikut (Santagiuliana, 2003: 141):

Eklesiologis: Sangat disadari bahwa keselamatan tidak saja merupakan urusan pribadi tetapi urusan komunitas. Karena itu karya pastoral Gereja dirancang dan dilaksanakan demi tercapainya suasana persekutuan di antara umat. Visi persekutuan tersebut ditegaskan dalam Konsili Vatikan II. Menurut visi tersebut, paroki sesungguhnya merupakan sebuah komunitas di mana umat hidup dalam suasana persaudaraan satu dengan yang lain. Karena itu semua karya pastoral paroki yang direncanakan dan dilaksanakan harus membantu dan mendorong umat untuk mengalami persekutuan sejati dengan Tuhan dan sesama di dalam Gereja.

Antropologis: Manusia diciptakan secara utuh rohani dan jasmani, jiwa dan badan. Karena itu karya pastoral berkaitan juga dengan usaha untuk membantu manusia mengalami keselamatan yang integral. Manusia dalam keutuhannya (jiwa dan badan) menjadi sasaran utama karya pastoral Gereja. Jadi, semua karya pastoral yang dirancang dan dilaksanakan itu, hendaknya menjawabi kebutuhan manusia secara utuh.

Sosio-politis: Gereja dipanggil untuk mengonkretkan "tanggung-jawab sosialpolitiknya". "Tanggung jawab sosial-politik" dimaksudkan sebagai pelayanan terhadap masyarakat yang juga merupakan kewajiban Gereja untuk berjuang demi pembebasan masyarakat yang berangkat dari situasi konkret di mana masyarakat hidup dengan segala persoalannya. Karena itu karya pastoral paroki harus menyentuh manusia dalam situasinya yang konkret: kapan dan di mana ia hidup.

Kosmis-Universal: Sejarah manusia dengan segala harapan dan kecemasannya adalah medan di mana Kerajaan Allah dibangun. Kaum kristiani tidak bisa menutup diri hanya dalam kemapanan Gereja demi privatisme. Karena itu harus dipahami bahwa wilayah termasuk di dalamnya lingkungan hidup, merupakan ruang vital di mana manusia merealisasikan eksistensinya. Itulah tempat di mana 
umat atau masyarakat mengarahkan dan membangun sejarahnya. Pada titik inilah lingkungan hidup menjadi sebuah bidang pastoral strategis yang harus diperhatikan agar keselamatan menjadi sebuah realitas yang nyata dialami oleh umat kini dan disini. Karya pastoral yang memiliki bobot keselamatan adalah karya pastoral yang mengajak dan mendorong umat untuk melihat dan menerima lingkungan ekologisnya sebagai bagian dari hidupnya sendiri yang harus dijaga dan dirawat.

Eskatologis: Karya pastoral yang direncanakan dan dilaksanakan oleh umat dengan segala potensi dan kemampuan yang dimilikinya tetap merupakan satu usaha yang harus diletakkan dalam konteks penyelenggaraan ilahi di mana Roh Allah diyakini sebagai penggerak utama. Dalam perspektif eskatologis, segala karya pastoral, apapun tingkat pencapaiannya, tetaplah karya yang terbatas, tidak sempurna. Allah-lah yang akan menyempurnakan segalanya.

\subsection{Lingkungan Hidup}

\subsubsection{Pemahaman Dasar tentang Lingkungan Hidup: Ekologi}

Ekologi merupakan ilmu yang mempelajari hubungan timbal balik antara organismeorganisme dan hubungan antara organisme-organisme itu dengan lingkungannya. Istilah ini diperkenalkan pertama kali oleh Haeckel pada tahun 1866. Definisi tersebut menggarisbawahi bahwa lingkungan hidup berhubungan dengan kependudukan dan sumber daya alam. Manusia maupun ciptaan nonhuman memiliki nilai intrinsik; keanekaan hayati memiliki nilai pada dirinya sendiri.Konsep dan pemahaman tersebut mengisyaratkan hal yang sangat fundamental, yakni upaya menjaga dan memelihara lingkungan hidup. Upaya untuk menjaga dan memelihara lingkungan hidup tidak bisa lagi dilakukan secara perseorangan, melainkan harus dilakukan secara bersama-sama dan diberi ciri organisasi. Ciri organisasi menjadi basis kekuatan untuk melawan kekuatan yang lain yang ingin merusakkan lingkungan dengan dalih demi peningkatan ekonomi. Oleh karena itu demi perbaikan lingkungan hidup perlu dilakukan perubahan kebijakan di bidang ekonomi, teknologi dan struktur-struktur ideologis; juga perlu ada penghargaan yang lebih mendalam terhadap mutu kehidupan. Hal itu bakal terjadi jika ada organisasi yang andal, yang menawarkan alternatif baru untuk menjaga kelestarian lingkungan (Hadiwardoyo, 2015:54).

\subsubsection{Akar Pengrusakan Lingkungan Hidup}

Masalah pengrusakan lingkungan hidup berawal dari sikap manusia yang memutlakkan kebutuhannya tanpa melihat kaitannya dengan faktor lain. Di satu sisi sumber daya alam merupakan sumber yang terbatas dan di pihak lain kebutuhan manusia tidak

memiliki batas. Pengalaman menunjukan bahwa tampaknya tidak ada pertimbangan yang komprehensif dalam mengelola sumber daya alam. Hidup manusia dewasa ini ditata bukan berdasarkan prinsip kebutuhan tetapi berdasarkan prinsip ketamakan atau kerakusan. Hidup yang ditata berdasarkan prinsip ketamakan dan kerakusan selalu berorientasi pada keuntungan 
pribadi tanpa berpikir tentang dampak negatifnya. Naluri sosialnya dikalahkan oleh kesombongan ekonomis yang cenderung menilai keselamatan manusia sebagai barang murahan. Pada titik ini sedang terjadi proses "komoditisasi" manusia serta lingkungannya. Manusia dan lingkungannya diperjualbelikan demi keuntungan ekonomis. Hidup yang telah diberikan oleh Tuhan dalam relasi dengan alam lingkungannya dicabik-cabik oleh manusia sendiri karena ambisi-ambisi sempit demi kepentingan pribadi dan kelompok. Patut disayangkan masyarakat yang menderita akibat bencana alam tampaknya hanya menjadi objek tangisan tetapi tidak didampingi untuk menjadi subjek pencari solusi yang melahirkan komitmen untuk mencegah terjadinya kerusakan lingkungan.

\subsubsection{Perbaikan Lingkungan Hidup}

Pentingnya menjaga keutuhan lingkungan merupakan isu global, yang juga saat ini diperjuangkan secara global pula. Ada sekian banyak lembaga sosial bertaraf nasional yang dengan sangat gigih memberikan animasi kepada masyarakat umum tentang pentingnya menjaga lingkungan hidup. Beberapa tahun lalu ada demonstrasi besar-besaran dari sekelompok pejuang lingkungan hidup di Belanda atas pengrusakan hutan di daerah tropis, termasuk di Indonesia. Pertanyaannya: mengapa bukan orang Indonesia yang melakukan demonstrasi tetapi justru warga Belanda? Paradigma dasar yang ada dalam pikiran warga Belanda jelas: alam merupakan satu sistem yang unsur-unsurnya saling terkait. Paradigma tersebut kemudian membuka kesadaran warga Indonesia bahwa hutan tropis Indonesia merupakan salah satu hutan tropis yang juga menentukan tingkat pemanasan global, yang pada gilirannya memengaruhi cuaca global (Setiawan, 2015: 27). Harus disadari bahwa penghargaan dan respek yang sepadan terhadap lingkungan pada akhirnya menciptakan kondisi alam lingkungan yang juga respek terhadap manusia. Hubungan ini tampaknya sulit untuk dijelaskan secara rasional tetapi dapat dialami secara faktual. Sejauh manusia ramah terhadap lingkungan, sejauh itu pula lingkungan ramah terhadap manusia (Hardiwadoyo, 2015:51).

\section{Katekis dan Tanggung Jawab Ekologis}

\subsection{Dasar Teologis Pastoral Ekologi}

Dasar teologis satu-satunya bagi Gereja untuk terlibat dalam gerakan menjaga keutuhan ciptaan adalah "peristiwa inkarnasi".Peristiwa inkarnasi menjadi titik tolak bagi Gereja untuk menilai secara positif realitas duniawi sebagai sarana untuk mencapai keselamatan yang utuh.Tentang ini, dokumen Vatikan II, Lumen Gentium mengatakan:

\footnotetext{
"Kristus satu-satunya pengantara di dunia ini telah membentuk Gereja-Nya yang Kudus, persekutuan iman, harapan dan cinta kasih, sebagai himpunan yang kelihatan. Ia tiada hentinya memelihara Gereja. Melalui Gereja, Ia melimpahkan kebenaran dan rahmat kepada semua orang. Adapun serikat yang dilengkapi dengan jabatan hirarkis dan Tubuh Mistik Kristus, kelompok yang tampak dan persekutuan rohani, Gereja di dunia dan Gereja yang
} 
diperkaya dengan kurnia-kurnia surgawi, janganlah dipandang sebagai dua hal, melainkan semua itu merupakan satu kenyataan yang kompleks dan terwujudkan karena perpaduan antara unsur manusiawi dan ilahi” (LG 8).

Kutipan dokumen Lumen Gentium di atas membawa Gereja pada refleksi yang lebih mendalam bahwa dalam dan melalui peristiwa inkarnasi Yesus Kristus masuk dalam ruang dan waktu dan karena itu ruang dan waktu menjadi "saat" dan "tempat" di mana manusia dapat mengalami keselamatan. Dalam konteks itu penghargaan terhadap lingkungan hidup, tempat di mana manusia membangun hidupnya, harus menjadi bagian dari perwujudan iman yang seharusnya diperjuangkan dan dihayati oleh setiap anggota Gereja.

Kekayaan dan kedalaman misteri inkarnasi tersebut harus membingkai seluruh karya pastoral Gereja, sehingga karya pastoral Gereja tetaplah merupakan karya pastoral yang integral yang menampilkan salah satu cirinya yang "kosmik-universal". Konsep ini menggarisbawahi kebenaran bahwa karya pastoral Gereja akan menjadi satu karya pastoral dalam arti yang sesungguhnya jika umat menyadari lingkungan hidup sebagai bagian dari hidupnya sendiri, yang harus dijaga serta dirawat demi kepenuhan hidupnya, dan selanjutnya dilestarikan untuk generasi yang akan datang. Karya pastoral yang demikian, akan membawa umat sampai pada penghayatan iman yang liberatif, bukan iman yang seremonial (Seputra, 2007: 73).

\subsection{Tanggung Jawab Ekologis Katekis}

Sebagai agen pastoral, katekis dipanggil untuk mengaplikasikan seruan Gereja berkaitan dengan lingkungan hidup. Dalam sidang Agung Gereja Katolik Indonesia (SAGKI) tahun 2005, Gereja Indonesia menunjukkan keprihatinan atas masalah lingkungan, baik yang berkaitan dengan hutan maupun nonhutan. Gereja Indonesia mengedepankan habitus baru yakni tumbuhnya kebiasaan yang senantiasa menghargai lingkungan. Karena itu berhadapan dengan berbagai macam aktivitas pengrusakan lingkungan hidup dalam pelbagai bentuknya, katekis dipanggil untuk terlibat secara aktif, menjaga keutuhan ciptaan, baik pada tahap animasi, maupun aksi-aksi konkret berdasarkan ajaran resmi Gereja (KWI, 2005: 277). Segala bentuk animasi dan aksi-aksi konkret yang dikemas oleh para katekis dalam berbagai bentuk pendampingan umat, diharapkan membawa umat sampai pada satu kesadaran tentang "tanggung jawab ekologis" yang harus dilaksanakan dalam hidup setiap hari. Dalam konteks itu, setiap katekis harus meyakini kebenaran ini bahwa: "absensi kehidupan, privatisme, pengurungan hidup" hanya dalam lingkup internal Gereja, tidak hanya terlarang, tetapi merupakan dosa.

Konsep itulah yang harus dimiliki oleh katekis dan diwartakan kepada umat sehingga semua orang Katolik bersama-sama berjuang untuk menata kehidupannya dan kehidupan bersama, bertolak dari realitas lokal, dari wilayah dimana ia tinggal dan berpartisipasi dalam menghadapi masalah-masalah sosial dalam masyarakat termasuk menjaga keutuhan lingkungan dalam kerja sama dengan semua pihak yang berkehendak baik. Dengan cara ini, 
dijamin hubungan yang "kritis-kreatip" antara Gereja dan wilayah serta lingkungannya. Hanya dalam hubungan yang stabil seperti ini Gereja dapat menegaskan dan sekaligus merealisasikan secara penuh "identitas teologisnya dan peran sosio-pastoralnya". Para katekis sesungguhnya merupakan tokoh kunci dalam mewujudkan peran sosial Gereja, kapan dan dimana saja mereka berkarya.

\section{Penutup}

Sebagai agen pastoral, tugas dan kehadiran seorang katekis tetap relevan dan kontekstual. Bidang pelayanan Gereja yang integral, yang menyentuh semua dimensi hidup manusia, menjadi alasan fundamental untuk menegaskan bahwa kehadiran katekis tidak akan ketinggalan zaman.Pergumulan umat saat ini berhubungan dengan lingkungan hidup, adalah juga pergumulan katekis. Seiring dengan pembaruan dan perkembangan visi pelayanan Gereja: dari cura animarum ke cura personarum dan akhirnya cura communitatum, maka tugas para katekis untuk membangun kesadaran umat tentang pentingnya menjaga lingkungan hidup, sesungguhnya bukanlah tugas tambahan, melainkan tugas fundamental yang mengalir dari missio canonica yang diterimanya untuk membantu umat mencapai keselamatan yang integral.

\section{Daftar Rujukan:}

\section{Dokumen}

Dekrit tentang Kerasulan Awam (Apostolicam Actuositatem).Dalam R. Hardawiryana. Pen.1993. Dokumen Konsili Vatikan II.Penerbit Obor, Jakarta.

\section{Buku-buku}

A. A.1988. Corso di Formazione per animatori di comunita ecclesiale di base. Edizione ChiesaMondo, Catania.

Chen, Martin. 2015. Spiritualitas Katekis dalam Dunia Dewasa Ini: Menjala di Laut Yang Lebih Dalam. Dalam Mukese, John Dami dan Frans Obon. Ed. Kirbat Baru untuk Anggur Baru. Menjala di Laut Yang Lebih Dalam. Nusa Indah, Ende.

Fallico, Antonio. 2006.Sulle Orme del Buon Pastore. edizioni Chiesa-Mondo.

Hardiwardoyo, Purwa.2015. Teologi Ramah Lingkungan, Sekilas tentang Ekoteologi Kristiani.Kanisius, Jogyakarta.

Lolonrian, Wilfridus. 2015.Tanggung Jawab Cendikiawan Katolik dalam Pembangunan. Dalam Lolonrian, Wilfridus. 2015. Berpihak pada Manusia Tersalib, Spiritualitas Fungsionaris Pastoral Awam. Bajawa Press, Yogyakarta.

Santagiuliana, Ampelio. 2003.Parrocchia Territorio Unita Pastorali. Edizioni Dehoniane Bologna.

Setiawan, Hendro. 2015. Awam Mau ke Mana? Jogyakarta, Kanisius.

Seputra, Widyahadi. 2007. Kajian Lingkungan Hidup, Tinjauan dari Perspektif Pastoral Sosial.Komisi PSE KWI. 
Sutam, Inosensius. 2015. Katekis Sebagai Misionaris Inter Gentes Berbasis Budaya Lokal. Dalam Mukese, John Dami dan Frans Obon. Ed. Kirbat Baru untuk Anggur Baru. Menjala di Laut yang Lebih Dalam. Nusa Indah, Ende.

Villata, Giovanni. 1998. Orientati dal Futura, Nuove forme di comunita fra parrocchie.Editrice Fosanno. 